much as possible to get informed about the factor which those natives hold in their archaic way of living.

It will be possible to draw a certain degree of the outline for the people in various places for selecting agricultural products or making idealistic eating-habit pattern by applying the results obtained from the investigation on Papuans.

Tropical diseases, famishing or population problem will effectively be solved if medical services and food supplying work together in good cooperation.

Tested paper method prepared for field research was used. The sensitivity of an individual tested material should be the mean of threshold. Each examines testes a material, then fills up the answering paper by himself in modernized area, or examiners fill up the papers in primitive areas. Examinees both male and female should be over 9 year-old and aged people were eliminated (there are not many people of over 40 year-old in primitive areas). One hundred natives were examined in each area. For bitter teste, phenylthiourea was used and differences among races concerning taste-blind were also examined.

Sweetness was highly tasted among the natives in high-temperature area, and decreasing of threshold due to the increasing of sugar-consumption (rising of modernization) was appearing. Sensitiveness of acidity (sourness) tends to increase along with the modernization. Taste-blind of bitterness decreases along with social modernizing and opening of a community. An independent race, supposed as East Melanesians of Solomon Sea islands, live in closed community has low degree of taste-blindness and considered to be different from Papuans.

Cannibals, Baining race, of New Britain island shows $100 \%$ of taste-blindness, and is considered as a different race from other races of that island.

Primitive cannibals living in the innermost part of New Guinea main island have no experience of taking salt and have no ability to discriminate even slightly salty taste.

The natives of this area are just as on the same level as the human being of the Neolithic age and that means they are on the primitive stage of taste sensitivity and correspond to the children of 2 to 3 year-old in modernized society.

Human flesh is fairly popular among them, but this fact should be considered from the view point of their custom came from shortage of food and regarded as a luxury rather than the aspect of animism.

\title{
THE MEDICAL STATUS AND FACTS EXPERIENCED IN EAST PAKISTAN
}

\author{
AKIRA NAKASHIMA \\ Second Department of Internal Medicine Kagoshima University \\ School of Medicine Kagoshima City, Japan
}

We have been in Chittagong, East Pakistan since June, 1968 as members of medical team for the Japanese engineers and their families staying in that country 
to engage in the construction of government-owned steel mill.

In that country we experienced miscellaneous what we call " tropical diseases" that can be seen in the Southeast Asian countries.

The climate in East Pakistan is, as is in the Southeast Asian countries, of high temperature and of high humidity that are closely related to the occurrence of tropical diseases.

The rainy season and the dry season set in alternately throughout a year. The average temperature is $28.0^{\circ} \mathrm{C}$ during rainy season and $27.0^{\circ} \mathrm{C}$ during dry season, while the percentage of humidity is $72.0 \%$ during rainy season and $63 \%$ during dry season. However, the maximum temperature usually rose to about $36.0-40.0^{\circ} \mathrm{C}$ and the maximum percentage of humidity to above $90.0 \%$ or higher. This high percentage of humidity is especially to blame for the outbreaks of tropical diseases.

East Pakistan is a flat country without high mountains. There are lots of rivers running through all over the country which are used as roads for transportation and traffic. In rainy season these rivers are often flooded by a heavy rain, that as a result give rise to epidemics, especially cholera and small pox, among people. High incidence of diseases such as malaria and Kala azar brought on by aquatic vectors and of diseases of water-borne-infection (cholera, dysentery and others) is supposed to be due mainly to poor hygiene and rivers that so often inundate.

Diseases of digestive tract such as amebic dysentery, bacillary dysentery, diarrhea of unknown cause and food poisoning etc. are frequently seen among Japanese living in East Pakistan because of being unable to obtain fresh foodstuff resulted from poor storage facilities available in Pakistan. Increased vitamin requirement in people living in East Pakistan with such high temperature and humidity is also to be watched carefully.

Cholera, small pox and malaria, among annoying tropical diseases that are prevalent in East Pakistan, are the most troublesome and hard-to-control maladies for the East Pakistani People. According to the government of East Pakistan there were 6,648 small pox patients in 1967 and 3,456 of them died while 424 people died of cholera out of 862 cases in the same year. It is also reported that from January through October in 1968 there were 7,387 small pox cases including 3,457 death cases and 1,579 cholera cases including 413 death cases. The government sources however recognized that these figures might be higher because of unreliable national census in connection with population and insufficient means of communication and traffic to give them correct informations on the outbreaks of the diseases in local areas.

Looking back to the past it was reported that 58,891 died of small pox in 1959 in both East and West Pakistan. As to cholera there were 29,691 deaths in 1948 and 27,132 deaths in 1953.

According to local news paper about 200 died of cholera in a small town of Comilla, East Pakistan within December, 1968.

It is also reported that about $50 \%$ of the newborn and infant mortality is due to malnutrition.

The government of Pakistan is making every effort to eradicate communicable diseases being prevalent in Pakistan with special emphasis on the control of mala- 
ria, small pox, cholera and tuberculosis. For that purpose there are WHO malaria center and SEATO cholera center in Dacca, capital city of East Pakistan. The SEATO cholera center is to eradicate malaria completely in East Pakistan by 1972.

Tuberculosis is the most unattended malady in Pakistan. A report available says about $3 \%$ of whole population are suffering from tuberculousis without undergoing any medical treatment because of religious, social and budgetary restriction.

It is strongly advised that to help develop Southeast Asian countries social and religious innovations are inevitable. Money alone can not be the solution for the development of these countries. Illiteracy of people is also a hindrance to the better hygiene and development of most Southeast Asian countries. 